\title{
FINITISM AND THE BEGINNING OF THE UNIVERSE
}

\section{Stephen Puryear}

\begin{abstract}
Many philosophers have argued that the past must be finite in duration because otherwise reaching the present moment would have involved something impossible, namely, the sequential occurrence of an actual infinity of events. In reply, some philosophers have objected that there can be nothing amiss in such an occurrence, since actually infinite sequences are 'traversed' all the time in nature, for example, whenever an object moves from one location in space to another. This essay focuses on one of the two available replies to this objection, namely, the claim that actual infinities are not traversed in nature because space, time and other continuous wholes divide into parts only in so far as we divide them in thought, and thus divide into only a finite number of parts. I grant that this reply succeeds in blunting the antifinitist objection, but argue that it also subverts the very argument against an eternal past it was intended to save.
\end{abstract}

Keywords: Space, time, continuity, infinity, creation, events

\section{Introduction}

The argument with which I will be concerned here has a long and distinguished history. Its proponents include John Philoponus (ca. 490-570), al-Kindi (ca. 800-870), Saadya Gaon (882-942), al-Ghāzāli (ca. 1056-1111), St. Bonaventure (ca. 1217-1274), Ralph Cudworth (1617-1688) and Richard Bentley (1662-1742). ${ }^{1}$ A version also appears in the proof of the thesis of Kant's first antinomy [1787: B454]. In our own day the argument has been revived by, among others, G. J. Whitrow [1978] and especially William Lane Craig, into whose kalām cosmological argument for the existence of God it figures as a major component [1979:102-10; Craig and Smith 1993: 4-35; Craig and Sinclair 2009; see also Huby 1971; Conway 1974]. As one might expect, the argument has also elicited a multitude of objections from various philosophers [see, e.g., Popper 1978; Bell 1979; Mackie 1982: 92-95; Smith

\footnotetext{
${ }^{1}$ On the history of the argument up through the seventeenth century, see Whitrow [1978] and Craig [1979:1-49].
} 
1987; Morriston 2002; Oppy 2006: 137-54]. Despite all that has been said, however, I think it would be fair to say that the dispute has reached something of a stalemate. As with many long-standing philosophical debates, this one has resolved into a clash of intuitions, in this case on the notoriously difficult topic of infinity. Neither side has yielded much ground and the prospects for further progress seem dim. Nevertheless, I will attempt to advance the debate by sidestepping the clashing intuitions about infinity and pressing a line of attack that has not yet been fully developed. I will argue that the most plausible response to this attack, the one endorsed by Craig, actually subverts the argument it was introduced in order to save.

\section{The Argument}

The argument I have in mind aims to establish that there is something incoherent in the very idea of a universe such as ours being eternal. The basic idea is this. If the universe had no beginning, then reaching the present moment would have involved something impossible, namely, the traversal of an infinite, or as Kant put it, the completion of an infinite series by 'successive synthesis' [1787: B454]. But obviously we have reached the present moment. ${ }^{2}$ So the universe must have had a beginning. More precisely, the argument can be put this way:

1. If the universe did not have a beginning, then the past would consist in an infinite temporal sequence of events.

2. An infinite temporal sequence of past events would be actually and not merely potentially infinite.

3. It is impossible for a sequence formed by successive addition to be actually infinite.

4. The temporal sequence of past events was formed by successive addition.

5. Therefore, the universe had a beginning.

\footnotetext{
${ }^{2}$ Though I have found it helpful in introducing this argument to rely on the premise that we have reached the present, this is not essential to the argument and does not appear in the more precise statement, which makes no reference to the present at all.
} 
In order to fix more precisely the idea of the temporal sequence of past events, let us stipulate that (i) each event in this sequence has the same finite duration, (ii) each event in the sequence includes everything that happens throughout the universe during that period, (iii) the events in the sequence are temporally non-overlapping and (iv) there are no time-gaps between consecutive events in the sequence. Given these simplifying assumptions, it seems clear that if the universe did not have a beginning, then the temporal sequence of past events would be infinite, as stated in (1).

Premise (2) makes the point that if the temporal sequence of past events had no beginning, then it would be actually and not just potentially infinite. Some philosophers appear to have thought otherwise. For instance, Aristotle and many of his followers held that matter (and thus the universe) is eternal. Yet they also disavowed actual infinities; for them, all infinities are potential infinities. From this point of view it would seem to follow that the temporal sequence of past events is only potentially infinite. Similarly, Aquinas upheld the (metaphysical) possibility of an eternal universe while denying the possibility of actually infinite multitudes [1268: 1a.7.4, 75-77; 1271]. He too would apparently have denied (2). Against these philosophers, proponents of the present argument have insisted that a beginningless temporal sequence of past events would have to be actually infinite because past events, unlike future events, have actually occurred [Craig 1979: 95-98; Whitrow 1980: 30-32]. An endless future would be potentially infinite in the sense that time would be always progressing, never ending. But the past is set in stone; so if it is infinite, the thought goes, it must be actually so.

Most critics of the argument have focused on (3), which denies that actually infinite sequences can be formed by successive addition. ${ }^{3}$ I will not attempt to survey their objections

\footnotetext{
${ }^{3}$ An alternative and historically less prominent version of the argument relies instead on the premise that there can be no actually infinite multitudes in nature. The points I will be making in $\S 3$ and beyond apply equally to this other version.
} 
here, but in order to give the reader a sense of the sorts of considerations which might lead one to embrace (3), let me briefly sketch just one argument for this premise. Consider a sequence of order type $\omega$, such as the natural numbers under the successor function. Though such a sequence can be represented using ellipses $\left(E_{1}, E_{2}, E_{3}, \ldots\right)$, it would be contradictory to suppose that it could be formed through successive addition, since no matter how many elements might be added, the sequence would perpetually remain finite, indeed would always fall infinitely far short of being actually infinite. However, if it is impossible to form a sequence of order type $\omega$ by successive addition, then by symmetry it should be impossible thus to form a sequence of order type $\omega^{*}$-i.e., the order type of the sequence of negative integers under less than — since the one is just the reverse of the other. Yet $\omega^{*}$ is exactly the order type the temporal sequence of past events would have if the universe had no beginning. Thus (3).

As I have indicated, many objections have been raised to (3) and to arguments such as the one just sketched. Meanwhile proponents of our finitist argument have offered replies, most of which are, to my mind, at least plausible if not actually cogent. Neither side has yielded much ground, and the debate has largely resolved into a conflict of foundational intuitions about actual infinities, an issue on which intelligent and mathematically sophisticated people have disagreed. Consequently, we seem to have reached something of an impasse. My goal here is to move beyond the impasse by setting the conflicting intuitions about infinity aside and criticizing the argument from a different angle. To do so I first need to introduce an important objection to the sort of finitism of which (3) is an expression.

\section{An Initial Objection}

Proponents of the argument under consideration here are finitists in the sense that they deny the possibility of forming or running through an actually infinite sequence in stepwise 
fashion. To use the traditional expression, they deny the possibility of traversing an actual infinite. According to some critics, however, this sort of finitism is refuted by the fact that we traverse actual infinites all the time [Morriston 2002: 162; Sinnott-Armstrong 2004: 42-43]. Consider the fact that things move from one point in space to another. In so doing, the moving object passes through an actual infinity of intervening points. Hence, motion involves traversing an actual infinite, and with all due respect to Zeno, we cannot reasonably deny that motion takes place. Accordingly, the finitist of this stripe must be mistaken. Similarly, whenever some period of time elapses, an actual infinite has been traversed, namely, the actual infinity of instants that make up that period of time. Once again, it cannot be denied that actual infinities are completable. So the finitist scruples upon which the argument against an eternal past rests are misguided. The argument fails.

This objection has merit, but it is not insuperable. In the first place, it assumes that finite magnitudes of space and time are composed of an infinite number of parts, whether unextended, like points or instants, or extended but simple. This yields the result that between any two points in space or time, there is an infinity of intervening parts that must be traversed in order to proceed from the one point to the other. But the finitist need not go along with this. She might instead affirm that space and time are quantized such that any finite spatial or temporal magnitude has only a finite number of minimal parts. On such a view, moving from one point to another would involve moving through only a finite number of intervening spaces, and any finite length of time would involve the occurrence of only a finite number of moments or chronons. In neither case would motion or the passing of time involve completing an infinite. Though Whitrow does not address this objection to his finitism as such, he does maintain that space and time are discrete, and so I suspect he would defend his finitism along these lines [1980: 200-5]. However, my concern in this essay will be with the other line of reply available to the finitist. 
According to this second line, space and time are indeed continuous, but it does not follow that between any two points in space or time there is an actual infinity of intervening parts or points. Instead, there is only a potential infinity of such parts. What makes such a position possible is the view that space and time and other continuous wholes are not composed of their parts but are instead prior to those parts. Consider the example of a line. It may strike us as natural to think of this line as composed of an infinity of points or infinitesimal line segments set end-to-end, much the way a house is composed of bricks. On the alternative view, however, the line is a whole which exists prior to any parts we may discern within it. Rather than being composed of these parts, the line is (in itself) a single whole from which parts are formed when a mind conceives of it as divided. Thus, given that finite minds can only mentally divide a whole a finite number of times, it follows that no continuous whole ever has more than a finite number of parts. More to the point, it follows that motion and the passage of time do not involve traversing an actual infinite, only a potential infinite. Once again finitism is safe.

This sort of conceptualism about the parts of a continuous whole was at least adumbrated by Aristotle [Physics, V.9, 239b5-32; VIII.8, 263a26-b8]. In Leibniz we find it explicitly articulated. He considers the idea of an infinity of points composing a continuum absurd, and so to avoid this absurdity makes two moves. First, he holds that composed things, such as matter and motion, are not continuous but discrete, even though they are divided to infinity. 'Matter is not continuous but discrete and actually divided to infinity, even if no assignable part of space is devoid of matter' [Leibniz 1705: 327]. Second, he denies that continuous things such as space and time are composed of their parts:

Yet space, like time, is not something substantial but something ideal, and consists in possibilities, i.e., the order of possible co-existents at any given time. And so there are no divisions in it, except those that the mind makes, and the part is posterior to 
the whole.

[ibid., emphasis mine]

For Leibniz, then, nothing composed is continuous and nothing continuous is composed.

Instead, continuous magnitudes have parts only in so far as the mind makes them, and since the mind can only ever make a finite number of such divisions, there is no worry that a continuum would be composed of an infinity of points.

In similar fashion, Craig has defended his finitism against the objection raised above by characterizing space and time as wholes which precede any parts or points we may identify within them:

[T]ime, like space, is infinitely divisible in the sense that division can proceed indefinitely, but time is never actually infinitely divided, neither does one arrive at an instantaneous point. If one thinks of a geometrical line as logically prior to any points which one may care to specify on it rather than as a construction built up out of points (itself a paradoxical notion), then one's ability to specify certain points, like the halfway point along a certain distance, does not imply that such points actually exist independently of our specification of them ... By contrast, if we think of the line as logically prior to any points designated on it, then it is not an ordered aggregate of points nor actually infinitely divided. Time as duration is then logically prior to the (potentially infinite) divisions we make of it. ${ }^{4}$

[Craig and Sinclair 2009: 112-3; cf. Craig and Smith 1993, 27-30]

As with Leibniz, Craig maintains that space and time are divided into parts only in so far as we specify such parts. But since we can only ever specify a finite number of such parts, it is false to suppose that an infinity is traversed whenever a thing moves from one point to

\footnotetext{
${ }^{4}$ I assume that when Craig speaks of time simpliciter in this passage and throughout his discussions of the finitist argument, he means duration in all its forms, which for him includes relative physical time (i.e., local time), absolute physical time (i.e., cosmic time) and absolute metaphysical time (i.e., God's time) [Craig 2001: 118-9, 202-40].
} 
another or when some period of time elapses. His finitism is thus exonerated.

It is worth emphasizing that in order for this reply to succeed, the divisions within a continuum must be supposed to exist only in so far as we actually think of them, or in other words, only in so far as we individually specify them. For otherwise the move would fall prey to an objection raised by Wes Morriston. He admits that the rejection of natural divisions within a continuum is 'probably the best reply available to Craig', but finds it unconvincing because 'what follows from the lack of natural boundaries within a region of space is not that the infinitely many sub-regions are not actually "there", but only that they are not "there" apart from a specified way of dividing things up' [Morriston 2002: 162]. Thus on Morriston's view, the fact that we can specify a rule for dividing a continuous magnitude such as a region of space into parts ad infinitum makes it the case that such magnitudes have or at least can have an actual infinity of parts. However, if the divisions within a continuum are there only in so far as we actually conceive them, as both Leibniz and Craig appear to be claiming, and not just in so far as we specify a procedure for conceiving them, then it will indeed follow that any given continuum resolves into only a finite number of parts.

A second point worth emphasizing, one which will loom large as we proceed, is that if continuous magnitudes do not divide into parts except in so far as we conceive or specify those divisions, it follows that space is in itself just one thing, that is, an indefinitely extended simple region. As it is conceived by us, space would indeed be divided into a number of smaller regions. But these divisions would exist only in our thought, not objectively or $a$ parte rei. The same would be true of time, and in order to preserve finitism, would have to be true as well of any continuous magnitudes that are traversed in nature. ${ }^{5}$

\footnotetext{
${ }^{5}$ As an anonymous referee points out, Craig's doctrine that time logically precedes the divisions we specify within it raises some thorny questions in connection with his presentism. For instance, why should we think that only present things exist, when the division within time between past and present is merely one we make? Do we determine what no longer
} 
Apart from the one ill-fated response of Morriston, critics have had nothing to say against Craig's defence of his finitism. However, it is just here, I believe, that things start to go seriously wrong for Craig. As I will argue in the next section, his endorsement of a conceptualism about the divisions within space and time commits him to a similar conceptualism about events. That is, it commits him to the view that all that has happened up till now is in itself just one long event, which divides into subevents only in so far as we specify or conceive divisions within it. But just as with space and time, this entails that the history of the universe up to the present divides into at most only a finite number of temporal parts, even if that history is (actually) infinite in duration. So ironically, the very move which allows Craig to deflect the objection to his finitism inadvertently undermines the argument that finitism was supposed to support. That is my argument in outline. Now for the details.

\section{From Time to Events}

First some preliminaries. For simplicity's sake, I will restrict myself in what follows to time and the temporal parts of events, though much of what I will say applies equally to space and the spatial parts of events. As for events, their nature is controversial. As it would take me too far afield to delve into the debates that have transpired in the large and complex literature on this subject, I will instead simply assume the view that events are changes. Besides being (in my opinion) the most intuitively plausible of the theories philosophers have defended, it is the view that Craig himself explicitly endorses and presupposes in his work. ${ }^{6}$ Finally, I will refer to the idea that time is prior to any parts we conceive within it as the Priority of the Whole with respect to Time (PWT), the opposing view as the Priority of the Parts with

exists by the way we divide time in thought? These are important questions, though I will not explore them here.

${ }^{6}$ See Craig [1979: 95]; Craig and Smith [1993: 24]; Craig and Sinclair [2009: 106]. For an extended discussion and defence of the view that events are changes, see Lombard [1986: 79-186]. 
respect to Time (PPT) and the corresponding views about events as, respectively, the Priority of the Whole with respect to Events (PWE) and the Priority of the Parts with respect to Events (PPE). The point I want to make in this section is simply that PWT entails PWE, so that Craig's endorsement of the former commits him to the latter. I will then conclude by arguing that at several points the finitist argument against an eternal past tacitly presupposes PPE, i.e., not-PWE, so that Craig's endorsement of PWT in fact undercuts the very argument his finitism was supposed to support.

As changes, events are intimately bound up with time. They take some time to occur, and typically have both a beginning and ending in time. To have a particular example before us, let us suppose that event $E$ is a certain raising of my right arm which begins at $t_{l}$ and ends at $t_{2}$. The point I want to emphasize here is that in order for $E$ to be a distinct event - distinct from what was happening with my arm prior to $t_{1}$ and after $t_{2}$ it is necessary that $t_{1}-t_{2}$ be a distinct period of time. But given PWT, there is no such distinct period apart from our conceptual activity: as it is in itself, time is just one long duration, without any temporal parts, not a sequence of intervals that add up to a longer one. It is not due to nature (physis) but to convention (nomos) that $t_{1}-t_{2}$ is a distinct part of time. Hence, to the extent that there is a distinct event $E$, it is not because nature divides the history of the universe up into distinct events; rather, we make those divisions by conceiving of history as so divided. Just as in itself time is merely one long duration, on this view it follows that history is in itself just one long event. PWT entails PWE.

The point can also be made this way: Setting aside spatial complexity, there can only be as many distinct events as there are distinct periods of time. But according to PWT, there is in nature only one period of time, that is, the whole of time. Thus in nature there can be only one event, the whole of history. Any subevents that we conceive within this one large event do not exist as such in nature but only in thought. Let us illustrate with another 
example. Suppose hypothetically that the universe has existed from eternity past and that throughout this time there has been a certain planet orbiting a certain star at regular (finite) intervals. Given this assumption, it seems natural to think that this planet's motion can be described not just as one infinitely long circular motion, but as an infinite sequence of circular motions, each of which began at one time and ended at another. However, this assumes that time naturally divides into this sequence of intervals, whereas according to Craig this is not the case. Hence we may well conceive of the history of the motion of this planet as an infinite sequence of finite motions, but as things are in themselves, there is really only one long motion that we conceptualize as a sequence.

The same conclusion can be approached from a different direction. If we take events to be changes, then they are just as infinitely divisible as time. For any such event, no matter how short, can always be divided into two subevents at any point we like. But if events are infinitely divisible and they are also composed of their (temporal) parts, then they must be not only potentially divisible to infinity but actually infinitely divided. In other words, if the parts are prior to the whole and the whole exists, then the parts must exist. But if the existence of the whole presupposes the existence of the parts, and the parts go to infinity, then there must actually be an infinity of parts. For the finitist, however, this presents a serious problem. For it would entail that any event is in fact an actually infinite sequence of subevents, so that the occurrence of the event involves the sequential occurrence of all the subevents. According to the finitist, however, it is impossible for any such sequence of events to occur. Thus, given that events are infinitely divisible, the finitist is forced to say that with events, as with space and time, the whole is prior to the parts. In other words, the finitist is committed to PWE.

The finitist might seek to avoid this conclusion by rejecting the assumption that events resolve into subevents ad infinitum. That is, she might maintain that while most events, including ordinary large-scale events such as picnics and football games, are indeed 
composed of a series of smaller events, every such composite event ultimately resolves into a finite number of simple, atomic events of some non-zero duration. ${ }^{7}$ On such a view, the parts of composite events would indeed be prior to the wholes they constitute. So PPE would hold true. But the resolution of wholes into parts would only go so far. Though temporally extended, the simple events would lack parts and thus would not themselves resolve into any smaller events. Every composite event would therefore resolve into only a finite number of subevents, and in no case would the occurrence of an event involve the sequential occurrence of an infinity of subevents. ${ }^{8}$

There is, however, a catch. For in affirming the atomicity of events, the finitist who offers this reply seems to commit herself to the atomicity of time as well. To see why, consider an atomic event $E_{1-3}$ that begins at $t_{1}$ and ends at $t_{3}$. If the period $t_{1}-t_{3}$ were not simple, then it would have at least two parts. For simplicity's sake, let us assume it has just two: $t_{1}-t_{2}$ and $t_{2}-t_{3}$. Now if $t_{1}-t_{2}$ is a proper part of $t_{1}-t_{3}$, then it must be a distinct period of time. But in that case, the change that takes place during $t_{1}-t_{2}$ would be a distinct event, $E_{1-2}$. It would not be necessary to wait until $t_{3}$ for an event to have occurred: already by $t_{2}$, a period of time would have elapsed, a change taken place and thus an event transpired. $E_{1-2}$ would therefore be a proper part of $E_{1-3}$, and contrary to our original supposition, $E_{1-3}$ would be composite, not simple. What this appears to show is that events cannot be simple and atomic unless time is also simple and atomic, or in other words, that events must have parts corresponding to the parts of the intervals during which they occur. ${ }^{9}$ And this is significant,

\footnotetext{
${ }^{7}$ That these atomic events could not be instantaneous follows from our assumption that events are changes and thus take some time to occur.

${ }^{8}$ Craig entertains a reply along these lines [Craig and Smith 1993: 27-29], but sets it aside in order to press instead the point that 'Time as a whole duration is . . logically prior to the (potentially infinite) divisions we make of it' [ibid., 29].

${ }^{9}$ A similar principle, that any physical object must have parts corresponding to the parts of the region it occupies, has recently been denied by a number of philosophers [see, e.g., Markosian 1998; Simons 2004; McDaniel 2007]. I sympathize with these dissidents; however, it seems to me that the dynamic nature of events renders the event-analogue of this
} 
because it means that finitism is now being defended by appealing to the idea that time is discrete. In effect, this reply amounts to an abandonment of the priority of the whole approach in favour of the alternative approach I have already set to one side.

\section{Back to the Finitist Argument}

From these considerations, it is clear that any finitist who responds to the objection raised in $\S 3$ by maintaining that continuous wholes are prior to their parts will have to say this not only about time (PWT) but about events (PWE). Yet it is important to realize that if PWE is granted, then the finitist can no longer consistently endorse the argument against an eternal past. For PWE thoroughly subverts that argument. Indeed it undercuts not one but three of its four premises. That argument, the reader will recall, goes like this:

1. If the universe did not have a beginning, then the past would consist in an infinite temporal sequence of events.

2. An infinite temporal sequence of past events would be actually and not merely potentially infinite.

3. It is impossible for a sequence formed by successive addition to be actually infinite.

4. The temporal sequence of past events was formed by successive addition.

5. Therefore, the universe had a beginning.

Now in the first place, PWE undermines (1). For if events do not divide into parts except in so far as we divide them in thought, then we must admit that just as time is in itself merely one long interval, the history of the universe up to the present is in itself just one long event. To the extent that it forms a sequence of events, it does so only in so far as we divide it into parts, and since we can only divide it a finite number of times, it forms at most only a finite

principle, that an event must have parts corresponding to the parts of the period during which it occurs, considerably more difficult to deny. I would like to thank an anonymous referee for pressing me to clarify this point and for comments which led to significant improvements in my treatment of the finitist reply under consideration. 
sequence. It might be supposed that the past could be divided into subevents en masse simply by specifying a way of dividing it into events of a certain duration; for instance, we could stipulate that the past divides into consecutive events lasting one second each [cf. Craig and Sinclair 2009: 106]. Regardless of what duration we chose, it would follow that if the universe had no beginning, the past would consist in an actually infinite sequence of such events. This, however, will not work. As I noted in $\S 3$, the finitist reply advocated by Craig can succeed only if it requires that divisions be individually specified, since otherwise it would be possible to specify an actual infinity of divisions within a finite region of space or time, in the way suggested by Morriston [2002: 162]. But the very same move that allows the finitist to block Morriston's objection also prevents the finitist from using a similar strategy to specify an infinity of divisions within the history of the universe. Hence, given PWE, premise (1) of the original argument is false. Even if the universe had no beginning, it would not follow that reaching the present involves traversing an infinite multitude. At most it would require traversing an infinite magnitude, something to which finitists have typically raised no objection.

In addition, PWE impugns premise (2), the claim that an infinite temporal sequence of past events would be actually and not merely potentially infinite. For if the universe had no beginning, and its history is in itself just one long event which we divide in thought, then the temporal sequence of past events into which that history divides would not be actually but only potentially infinite. It would be actually finite, but always further divisible and thus potentially infinite. From this point of view, Aristotle and Aquinas were in a sense right to hold that an eternal past would be only potentially infinite.

Finally, PWE undercuts premise (4), according to which the temporal sequence of past events was formed by successive addition. To characterize the past as a sequence of events formed by addition is to presuppose that the parts are prior to the whole (PPE). But if 
the whole is in fact prior to the parts, then the temporal sequence of past events is not formed by addition but by division.

In view of these points, I conclude that Craig's response to the anti-finitist objection introduced in $\S 3$ thoroughly undermines the very argument that finitism was supposed to support. The possibility of course remains that space, time and change (events) are discrete. I have not attempted to cast doubt on this alternative, and so I cannot claim to have refuted the original argument tout court. However, I have argued that Craig's position is incoherent and that, in a way that had not previously been noticed, the finitist argument for a beginning of the universe tacitly presupposes that space, time and change are discrete. Whether this latter position is plausible I will not take up here, but given how widely philosophers and physicists have affirmed the continuity of space and time, this has to be considered a serious mark against the finitist argument. ${ }^{10}$

North Carolina State University

\section{References}

Aquinas, Thomas 1268 (2006). Aquinas: Summa Theologiae, Questions on God, ed. Brian

Davies and Brian Leftow, Cambridge: Cambridge University Press.

Aquinas, Thomas 1271 (1998). On the Eternity of the World, in Thomas Aquinas: Selected Writings, ed. Ralph McInerny, London: Penguin Classics: 710-7.

Aristotle 1984. The Complete Works of Aristotle, 2 vols., ed. Jonathan Barnes, Princeton: Princeton University Press.

Bell, John 1979. The Infinite Past Regained: A Reply to Whitrow, British Journal for the

\footnotetext{
${ }^{10}$ For helpful feedback on earlier versions of this material I would like to thank John Carroll, Alan Nelson, my audience at the 2014 North Carolina Philosophical Society Meeting at UNC-Chapel Hill and two anonymous referees for this journal.
} 
Philosophy of Science 30/2: 161-72.

Conway, David A. 1974. Possibility and Infinite Time: A Logical Paradox in St Thomas' Third Way, International Philosophical Quarterly 14/2: 201-8.

Craig, William Lane 1979. The Kalām Cosmological Argument, London: Macmillan.

Craig, William Lane 2001. Time and the Metaphysics of Relativity, Dordrecht: Kluwer Academic Publishers.

Craig, William Lane and James D. Sinclair 2009. The Kalam Cosmological Argument, in The Blackwell Companion to Natural Theology, ed. William Lane Craig and J. P. Moreland, Oxford: Blackwell: 101-201.

Craig, William Lane and Quentin Smith 1993. Theism, Atheism and Big Bang Cosmology, Oxford: Oxford University Press.

Huby, Pamela M. 1971. Kant or Cantor: That the Universe, if Real, Must Be Finite in Both Space and Time, Philosophy 46/176: 121-32.

Kant, Immanuel 1787 (1998). Critique of Pure Reason, ed. Paul Guyer and Allen Wood, Cambridge: Cambridge University Press.

Leibniz, Gottfried Wilhelm 1705 (2013). Leibniz to De Volder, 11 October 1705, in The Leibniz-De Volder Correspondence, ed. Paul Lodge, New Haven: Yale University Press: $325-7$.

Lombard, Lawrence Brian 1986. Events: A Metaphysical Study, London: Routledge and Kegan Paul.

Mackie, J. L. 1982. The Miracle of Theism, Oxford: Oxford University Press.

Markosian, Ned 1998. Simples, Australasian Journal of Philosophy 76/2: 213-26.

McDaniel, Kris 2007. Extended Simples, Philosophical Studies 133/1: 131-41.

Morriston, Wes 2002. Craig on the Actual Infinite, Religious Studies 38/2: 147-66.

Oppy, Graham 2006. Arguing about Gods, Cambridge: Cambridge University Press. 
Finitism and the Beginning of the Universe

Popper, Karl 1978. On the Possibility of an Infinite Past: A Reply to Whitrow, British Journal for the Philosophy of Science 29/1: 47-48.

Simons, Peter 2004. Extended Simples: A Third Way Between Atoms and Gunk, The Monist 87/3: 371-84.

Sinnott-Armstrong, Walter 2004. There Is No Good Reason to Believe in God, in God? A Debate between a Christian and an Atheist, ed. William Lane Craig and Walter SinnottArmstrong, Oxford: Oxford University Press: 31-52.

Smith, Quentin 1987. Infinity and the Past, Philosophy of Science 54/1: 63-75; reprinted in Craig and Smith 1993: 77-91.

Whitrow, G. J. 1978. On the Impossibility of an Infinite Past, British Journal for the Philosophy of Science 29/1: 39-45.

Whitrow, G. J. 1980. The Natural Philosophy of Time, $2^{\text {nd }}$ edition, Oxford: Oxford University Press. 